\title{
Aposentadoria do Escritor
}

ALMEIDA FISCHER

Presidente da Associação Nacional

de Escritores

Coube ao ilustre Ministro Jarbas Passarinho, quando titular da pasta do Trabalho e Previdência Social, encaminhar as primeiras providências no sentido de atender a uma velha aspiração dos escritores brasileiros: sua aposentadoria como trabalhador autônomo. Ainda em sua gestão naquele Ministério assegurou ao escritor, depois de estudos realizados, o direito de aposentar-se pelo Instituto Nacional de Previdência Social, com trinta e cinco anos de atividades profissionais (cinco vêzes o salário-mínimo regional) ou com trinta anos de trabalho (oitenta por cento de cinco saláriosmínimos da região).

Foi sem dúvida uma conquista das mais importantes dos homens de letras do Brasil - que contaram para isso com a boa vontade e a compreensão do Govêrno -, que tem beneficiado numerosos trabalhadores do áspero ofício de escrever, muitos dêles tão necessitados dessa ajuda nos anos de vida que Ihes restam. Velhos e famosos lidadores das letras ou já se aposentaram ou estão cuidando do papelório necessário a fazê-lo. As primeiras aposentadorias foram concedidas ainda na gestăo do Ministro Jarbas Passarinho à frente da pasta do Trabalho e Previdência Social.

Os trabalhadores autônomos, admitidos nessa qualidade pelo Conselho Diretor do Departamento Nacional da Previdência Social, de há muitos anos tinham assegurado seu direito a aposentadoria por tempo de serviço após trinta anos de trabalho, com proventos de $80 \%$ sôbre o salário-base de contribuição ou, após trinta e cinco anos, com $100 \%$. A Lei n 3.807 , de 26 de agôsto de 1960 (Lei Orgânica da Previdência Social), reconheceu êsse direito, em seu artigo $5^{\circ}$, item IV.

Os escritores, porém, ainda não eram reconhecidos como trabalhadores autônomos. Outras categorias profissionais também não o eram. A luta por êsse direito, por parte dos escritores, desenvolveu-se por muitos anos. A Previdência Social não existia para o escritor, nessa qualidade específica. 
Em grande parte pelo desinterêsse da maioria, que não prescindia dela porque a desfrutava em função de outra qualidade profissional. É bem verdade que ser escritor ainda não constituía própriamente uma profissăo, vez que pouquíssimas pessoas conseguiam manter-se com o produto de seus livros e de seus artigos. As edições de livros - salvo honrosas exceções - não iam além dos dois mil exemplares.

O desenvolvimento geral do pais fêz com que aumentasse o número de leitores e se ampliasse 0 de casas editôras. A indústria gráfica brasileira modernizou-se bastante, melhorando sua capacidade de produção e a qualidade da composição e impressão de livros. As tiragens foram aumentando gradativamente e, em nossos dias, não mais se publicam livros, com propósitos comerciais, de menos de cinco mil exemplares. Isso porque os livros são agora compostos a frio e impressos em offset. Tiragens inferiores e cinco mil exemplares encarecem sobremaneira o seu custo unitário, vez que os fotolitos e as chapas de gravação têm alto preço.

Os escritores, atualmente, garantem sua subsistência e de seus familiares redigindo verbêtes para dicionários e enciclopédias, escrevendo para revistas especializadas e para jornais. As editôras, que antes não pagavam di- reito autoral, salvo exceções, hoje o fazem normalmente, em sua maioria. As poucas editôras que ainda burlam o autor, por tôdas as formas possiveis, não merecem êsse nome. Enfim, o escritor constitui, agora, uma categoria profissional, embora a maioria ainda se dedique também a outros ofícios.

O Decreto-lei $n \div 66$, de 21 de novembro de 1966, que alterou disposiçöes da Lei n: 3.807 , de 26 de agôsto de 1960 - que quando baixado ainda não beneficiava o escritor -, estabeleceu, em seu artigo 19: "Entende-se por "salário de contribuição": ...

II - o salário-base fixado para os trabalhadores autônomos e para os facultativos". Em seu artigo 77 , dispôs: "O salário-base será fixado pelo Departamento Nacional da Previdência Social, ouvido o Serviço Atuarial e os órgãos de classe, quando houver, devendo ser atendidas nas respectivas tabelas as peculiaridades das diversas categorias de trabalhadores e o padrão de vida de cada região." Com base nesses dispositivos da Legislação Orgânica da Previdência Social, o Conselho Diretor do Departamento $\mathrm{Na}$ cional da Previdência Social aprovou, por unanimidade, em sessão realizada em 14 de dezembro de 1967, quando titular do Trabalho e Previdência Social o escritor e Ministro Jarbas Passarinho, a Resolução n! 876, que "estabelece critério geral da fixação de sa- 
lário-base de contribuição dos trabalhadores autônomos, e dá outras providências". Após vários consideranda, - Conselho resolveu:
"1 - Fixar, segundo a tabela abaixo, os salários-base de contribuição dos trabalhadores autônomos nelas mencionados: 1

\section{I - PROFISSIONAIS LIBERAIS}

\begin{tabular}{|c|c|c|}
\hline $\begin{array}{l}\text { Classes } \\
\text { Profissionais }\end{array}$ & $\begin{array}{c}\text { Tempo de Atividade } \\
\text { Profissional }\end{array}$ & $\begin{array}{l}\text { Salário-base } \\
\text { (Em salários-mínimos } \\
\text { regionais) }\end{array}$ \\
\hline $\begin{array}{l}\text { Advogados } \\
\text { Assistentes Socials } \\
\text { Atuários } \\
\text { Autores Teatrais } \\
\text { Bibliotecários } \\
\text { Compositores } \\
\text { Contabilistas } \\
\text { Economistas } \\
\text { Enfermeiros } \\
\text { Engenheiros } \\
\text { ESCRITORES 2 } \\
\text { Estatisticos } \\
\text { Farmacêuticos } \\
\text { Jornalistas } \\
\text { Médicos } \\
\text { Odontologistas } \\
\text { Parteiros } \\
\text { Professôres } \\
\text { Protéticos dent. } \\
\text { Químicos } \\
\text { Veterinários } \\
\text { Técnico de Administração }\end{array}$ & $\begin{array}{l}\text { Até } 2 \text { (dois) anos } \\
\text { De } 2 \text { (dois) a } 15 \\
\text { (quinze) anos }\end{array}$ & 4 (quatro) \\
\hline
\end{tabular}

2 - Estabelecer que qualquer pedido de alteração dos valôres fixados, seja para mais ou para menos, em relação a qualquer classe profissional, só será considerado se fôr apresentado por órgão representativo da classe, devidamente acompanhado de estatisticas de rendimento de trabalho, de autenticidade irrecusável, não sendo suficiente a simples declaração dos interessados."

(1) Transcrevemos apenas a tabela de interêsse específico para 0 assunto.

(2) 0 destaque em caixa alta é nosso. 
Afinal, depois de tanto tempo, o escritor se vê reconhecido como trabaIhador autônomo, com todos os direitos aos benefícios da Previdência Social, inclusive a aposentadoria com trinta ou trinta e cinco anos de serviço. Os órgãos de classe passaram a cuidar mais sèriamente dos interêsses dos escritores e estão nascendo as Associações Profissionais de Escritores, que se transformarão, oportunamente, em sindicatos.

Para aposentar-se, o escritor deverá comprovar o exercício da atividade por trinta ou trinta e cinco anos. $O$ artigo 32 da Lei no $3.807 / 60$, não alterado pelo Decreto-lei $n$ ? 66 , de 21 de dezembro de 1966, estabelece, em seu $\S$ 10: "Em qualquer caso (trinta ou trinta e cinco anos de serviço), exigirse-á que o segurado tenha completado 55 (cinqüenta e cinco) anos de idade".

As dificuldades que os escritores, com tempo de serviço suficiente para aposentar-se, têm encontrado dizem respeito à comprovação de sua atividade por tantos anos. Revistas e jornais em que trabalharam como escritores (e não como jornalistas, recebendo por trabalhos escritos e não como empregados) deixaram de circular há muitos anos, seus proprietários faleceram e não há nenhum documento comprobatório de que seu trabalho foi remunerado. Há trinta anos atrás os pagamentos por trabalhos literários eram quase simbólicos e feitos através de "vales". A única prova do exercício da profissão reduz-se a recortes de jornais e revistas ou cópias xerográficas de seus trabalhos publicados, obtidas em geral de maneira penosa em bibliotecas públicas ou particulares ou em arquivos de instituições culturais. Muitos escritores estão se valendo da justificação judicial, com provas testemunhais, para superar tais dificuldades.

A mulher escritora poderá aposentar-se com trinta anos de serviço, recebendo proventos integrais, segundo dispõe a Resolução do INPS n? 501.2 , de 1 \% de novembro de 1967, e o homem escritor poderá contar para êste fim o tempo de serviço militar, conforme dispõem as Resoluções 68 , de 17 de fevereiro de 1970, e 279, de 2 de julho do mesmo ano, ambas do Conselho Diretor do Departamento Nacional da Previdência Social.

Os benefícios assegurados ao escritor, na qualidade de trabalhador autônomo, já estão sendo pleiteados por outras categorias profissionais. Jornalistas requereram recentemente ao $\mathrm{Mi}$ nistério do Trabaiho o direito de aposentar-se com cinco salários-mínimos regionais, à semelhança do que se assegura aos escritores. Em parecer de uso interno no Ministério do TrabaIho e Previdência Social, a Assessoria competente no assunto manifestou-se contràriamente à pretensão. Diz o douto parecer que " 2 . Os jornalistas profissionais são empregados cuja situação é regulada pelos arts. 59 e 63 do RGPS (Regulamento Geral da Previdência Social) e modificações posteriores. 3. Os escritores são autônomos, como tal expressamente considerados na Resolução do Conselho Diretor do DNPS número 876, de 14-12-67." Mais adiante, afirma o parecer: "5. Para os jornalistas profissionais, as suas aposentadorias são calculadas sôbre aquilo que de fato receberam. Se pouco 
receberam das emprêsas jornalísticas, só sôbre êsse pouco contribuíram: pequeno é o valor da aposentadoria. 6 . Já quanto aos escritores, suas contribuições são fixadas com base em múltiplos progressivos de salário-mínimo, isso em função do tempo de atividade profissional, até um máximo de 5 salários-mínimos regionais, depois de 15 anos de exercício da atividade específica." Mostra o parecer a impossibilidade de assemelhação, uma vez que não sendo os jornalistas autônomos e sim empregados uma complementação de contribuições pretéritas ou futuras, visando ao quantum do benefício, implicaria em contribuição idêntica da emprêsa empregadora.

Beneficiados pela aposentadoria já estão grandes nomes da literatura brasileira, entre os quais Afrânio Coutinho, Adonias Filho, Alceu Amoroso Lima, Álvaro Lins (falecido no ano passado), José Honório Rodrigues, Octa- vio de Faria e Afonso Arinos de Melo Franco - o primeiro grupo a se aposentar como autônomo - e Dinah Silveira de Queiroz, Rachel de Queiroz, Nelson Omegna, Luiz Viana Filho, Francisco de Assis Barbosa, Raymundo Magalhães Júnior, Lúcia Benedeti, Clarice Lispector, Elisa Lispector, J. G. de Araújo Jorge e Umberto Peregrino.

A verdade é que, com a permissibilidade de o escritor contribuir, como trabalhador autônomo, para a Previdência Social, os que vivem - ou complementam o orçamento doméstico - no duro ofício de escrever foram grandemente beneficiados. Ser escritor já não representa uma atividade marginal, e muitas vêzes perigosa, para se integrar no campo normal do trabalho honesto e honroso de todos os brasileiros que buscam, espremendo o cérebro ou de outra forma, construir uma pátria grande e progressista para os seus filhos, para o seu povo. 
